\title{
Dehiscent scar in the lower uterine segment after Caesarean section and IVF infertility treatment: $A$ case report
}

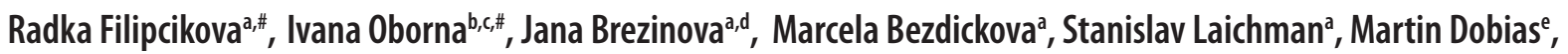 \\ Zdenka Blazkova ${ }^{a}$, Blazena Hladikova', Dalibor Pastucha ${ }^{f}$
}

\begin{abstract}
Aims. Caesarean section is the most common obstetric operation associated with short and long term risks, one of which is uterine scar dehiscence. In this case report we describe four cases of in vitro fertilization and embryo transfer $(\mathrm{IVF}+\mathrm{ET})$ treatment where the embryo was transferred into the uterus with known scar dehiscence in the lower uterine segment after a previous Caesarean section (SC).

Methods. All transfers of embryos were ultrasound guided directly into the middle of uterine cavity. All resulting pregnancies continued without problems related to the dehiscent scar and babies were delivered in the third trimester by elective/emergency SC.

Results. Our cases suggest that IVF + ET can be offered as an infertility treatment option despite a dehiscent scar in the lower uterine segment after previous SC.
\end{abstract}

Key words: uterine anatomy, lower uterine segment, scar dehiscence, IVF, transfer of embryo

Received: July 3, 2012; Accepted wiht revision: January 4, 2013; Available online: February 14, 2013

http://dx.doi.org/10.5507/bp.2013.001

\author{
${ }^{a}$ Department of Anatomy, Faculty of Medicine and Dentistry, Palacky University Olomouc, Czech Republic \\ ${ }^{b}$ Department of Obstetrics and Gynaecology, Faculty of Medicine and Dentistry, Palacky University Olomouc \\ 'Fertimed Olomouc \\ ${ }^{d}$ Arleta IVF, Kostelec nad Orlici \\ ${ }^{e}$ Department of Forensic Medicine and Medical Law, Faculty of Medicine and Dentistry, Palacky University Olomouc \\ ${ }^{f}$ Neonatal Unit, Faculty of Medicine and Dentistry, Palacky University Olomouc \\ "The authors contributed equally to the work \\ Corresponding author: Ivana Oborna, e-mail: ivana.oborna@upol.cz
}

\section{INTRODUCTION}

Caesarean section is the most frequent obstetric operation performed for various reasons such as late pregnancy or during unsuccessful vaginal delivery. Worldwide, numbers of SC are steadily increasing with improvements in surgical and anaesthetic techniques and, routine use of antibiotic and antithrombotic prophylaxis. It is wellknown that different surgical approaches e.g. blunt vs. sharp dissections, transverse lower uterine segment incision vs. other incisions, single vs. double layer uterine closure, continuous vs. interrupted suture of the uterus can markedly influence the healing process ${ }^{1}$. However, conditions such as emergency SC and infection can affect healing of the uterus even more ${ }^{2}$.

Like all operations, SC can be associated with short and long term risks, one of which is uterine scar dehiscence. This may present as an acute event during the antenatal, intrapartum or postpartum period ${ }^{3}$. Women with a dehiscent lower segment scar are also at higher risk of implantation in the scar $^{4}$, placenta accreta development or placenta praevia ${ }^{5}$. Uterine scar dehiscence can also cause prolonged menstrual bleeding if the defect serves as a reservoir for blood ${ }^{6}$.

Many authors suggest evaluating the lower uterine segment in late pregnancy to support the physician's decision on SC or vaginal delivery, and to explain or justify such decision to the patient ${ }^{7-9}$. Other authors believe the assessment of scar defect should be done on the non-pregnant uterus, either by ultrasonography, sonohysterography or MRI (ref. ${ }^{10-13}$ ).

There is no clear agreement for dealing with such asymptomatic dehiscence when it is found on the non-pregnant uterus in case the woman plans another pregnancy in the future. Donnez et al. ${ }^{12}$ described successful laparoscopic repair of dehiscent uterine scar in three symptomatic women. Others prefer the transvaginal approach, but no proof of its necessity or utility has been found ${ }^{14}$.

In this report we describe our approach to four women who were referred to IVF treatment because of secondary infertility for various reasons and who previously delivered by one SC (three patients) or two SC (one patient). In all these cases, the dehiscent uterine scar was detected during the infertility evaluation.

The ultrasound description of the lower uterine segment of the non-pregnant uterus was done according to Ofili-Yebovi et al. The uterus was examined in the longitudinal plane with identification of the internal os, the depth of the scar and the thickness of the adjacent myometrium. The loss of more than $50 \%$ of myometrium at the scar level was classified as severe ${ }^{11}$. 


\section{CASE REPORTS}

\section{Patient No. I}

A 33 year old woman was referred for IVF treatment for tubal factor (right salpingectomy (SE), left hydrosalpinx). Emergency SC had been performed 4 years ago due to foetal hypoxia, with no complications after the operation. A severe dehiscent scar was diagnosed by ultrasound (US) during the infertility evaluation (Fig. 1). Two unsuccessful trials for transvaginal repair of dehiscent uterine scar were performed with a 4 month interval between operations. The fibroid tissue was cut and the defect was sutured with separate stitches. The patient required IVF treatment and after explanations of all possible risks of pregnancy in a uterus with a dehiscent scar and signing the written consent, IVF treatment was performed. Ultrasound guided single embryo transfer (ET) was performed after 5-day cultivation directly into the middle of the uterine cavity. Ten days later the hCG level was positive and in due time the gestational sac (GS) in the uterine cavity was found (Fig. 2). The pregnancy proceeded without any complication and the uterine scar was evaluated every two weeks until week 38 when the elective $\mathrm{SC}$ was performed. Within the operation a complete dehiscent scar $5 \mathrm{~cm}$ long was seen with visible membranes. The healthy newborn was delivered with normal Apgar score for 10.The uterine closure was in double layers with continuous sutures. Postoperative care was uneventful. Three months later transvaginal US shown only minimal myometrial thinning in the lower uterine segment.

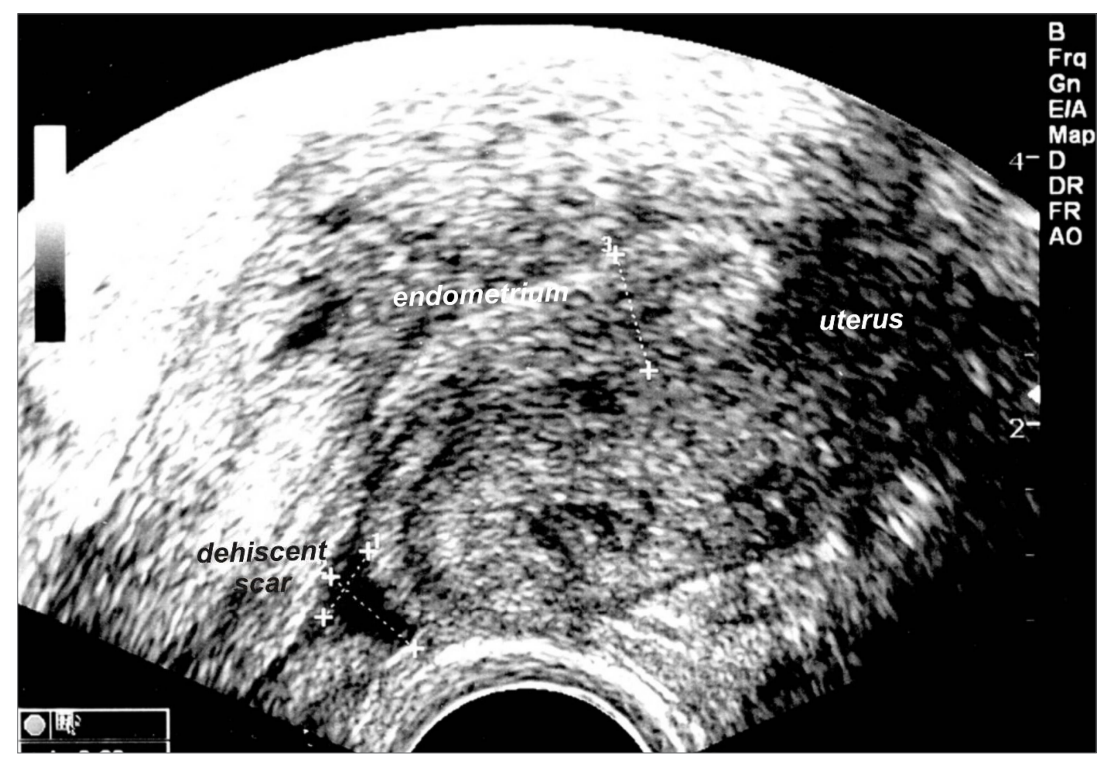

Fig. 1. A longitudinal view of the uterus in the late follicular phase with the dehiscent scar in the lower uterine segment.

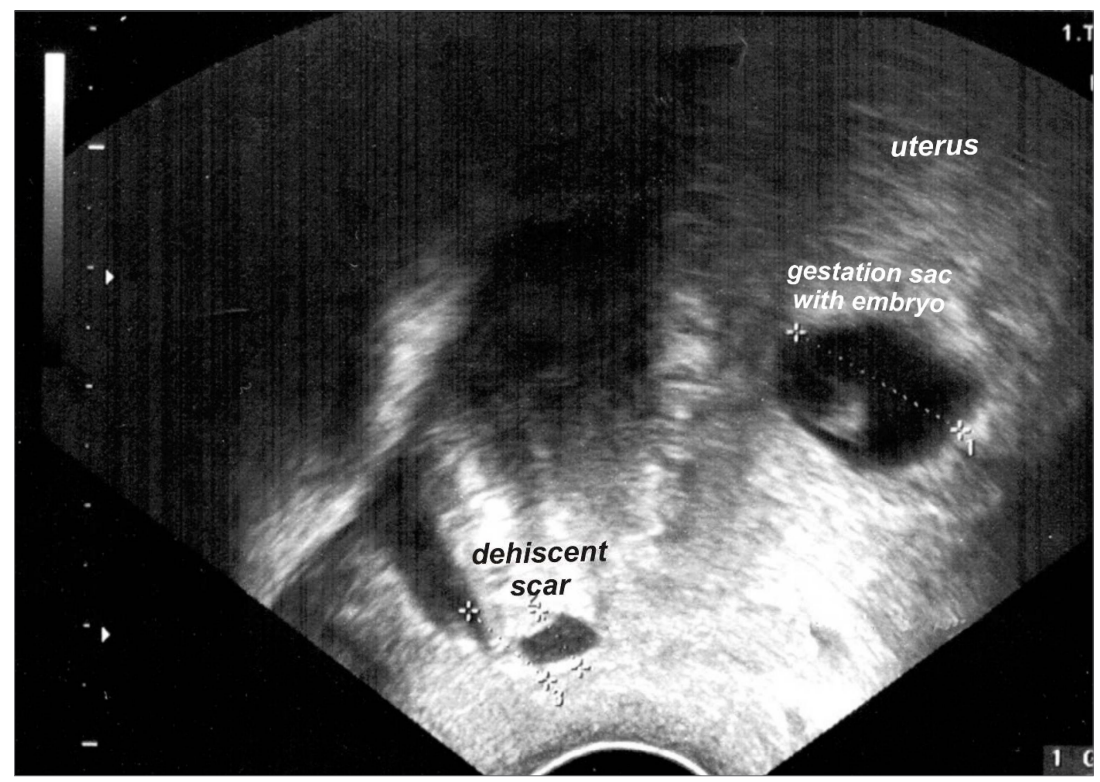

Fig. 2. A longitudinal view of the uterus with dehiscent scar in the lower uterine segment in the week 6 of pregnancy. 


\section{Patient No. II}

A 27 year old woman was referred for IVF treatment for both male and tubal factors (right SE for ectopic pregnancy, left hydrosalpinx). Emergency SC had been performed 3 years ago for foetal hypoxia. Despite prophylactic use of antibiotics, she had had a fever and a haematoma in the abdominal wall had to be emptied. A dehiscent scar on the retroverted uterus was diagnosed during infertility evaluation by ultrasound (US). One unsuccessful attempt at transvaginal repair of the dehiscent uterine scar was made. Possible consequences and risks of IVF treatment and pregnancy were explained to the couple. After signing the informed consent, successful IVF treatment with ultrasound guided transfer of single embryo was performed. Pregnancy proceeded without any complication until the $37^{\text {th }}$ week. The uterine scar was monitored by US every 4 to 2 weeks. The emergency SC with prophylactic use of antibiotics was performed for uterine contractions. The uterus was opened in the dehiscent scar. The healthy newborn was delivered with normal Apgar score for 9. The uterine closure was done in double layers with continuous sutures. There were no postoperative complications and patient was discharged day 4 after surgery. Three months later, dehiscent scar was found again by transvaginal US.

\section{Patient No. III}

A 28 year old woman with a new male partner with severe male factor infertility was referred for infertility treatment. Two elective SC had been performed 5 and 3 years ago for cephalo-pelvic disproportion. One of her complaints was also painless spotting 3-4 days after menstruation. The US revealed severe dehiscent scar. After explanation of the scar dehiscence and its consequences, the couple signed written informed consent and IVF treatment with single US guided ET was performed. The pregnancy proceeded without complications until the $37^{\text {th }}$ week with uterine scar monitoring every 4 to 2 weeks. Elective SC was performed in the $39^{\text {th }}$ week of pregnancy. The uterus was opened in the dehiscent scar in the lower uterine segment. The healthy newborn was delivered with a normal Apgar score for 10 . The uterine closure was done in double layers with continuous sutures. There were no postoperative complications and patient was discharged day 5 after surgery. Three months later transvaginal US found no dehiscence.

\section{Patient No. IV}

A 35 year old obese (BMI 34) woman asked for transfer of cryopreserved embryos from a previous successful IVF cycle when an emergency SC had to be performed for preeclampsia (PET) in a twin pregnancy in the $33^{\text {rd }}$ gestational week. The US also revealed a dehiscent scar. After explanation of scar dehiscence and its consequences, the

couple signed written consent and single US guided transfer of cryopreserved- thawed embryo in cleavage stage was performed. Pregnancy proceeded without complication with regular 4 week monitoring of uterine scar until the $31^{\text {st }}$ week when for PET and gestational diabetes $\mathrm{SC}$ had to be performed again. The immature newborn needed care at the intensive neonatal unit. A large subfascial haematoma which was found on day 3 after operation, although the drainage of this space was provided, required revision of the abdominal wall. The patient was discharged from the hospital day 8 after SC. She did not show up for US follow up of the scar.

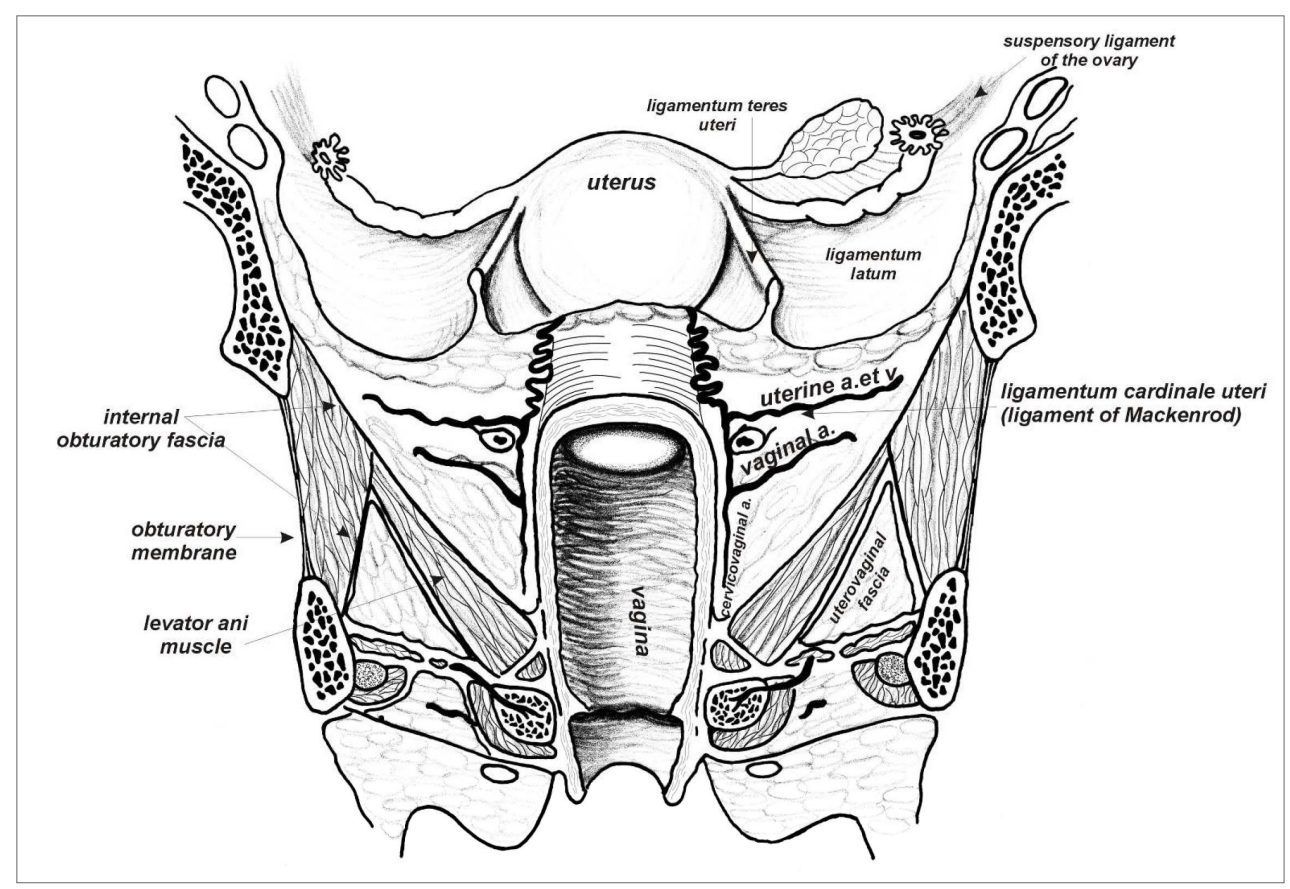

Fig. 3. Scheme of the blood supply of the uterus and its suspensory ligaments. 


\section{DISCUSSION}

The vascular supply of the uterus is provided by two sources, the uterine artery and the ovaric artery, which create numerous mutual anastomoses. The uterine artery, a branch of the internal iliac artery runs in the lower part of ligamentum latum uteri. Along the sides of the uterine cervix, the uterine artery splits up into the ascending and descending parts (Fig. 3). The ascending part is represented by the uterine artery itself, which is intensely winding along the edge of the uterus up to the uterine horns. The descendent part towards the uterine cervix runs as the cervicovaginal artery which is not winding. In the region of the uterine isthmus it links with the opposite artery and creates the circle arteriosus Huguieri ${ }^{15}$. The resilience of the pelvic connective tissue, ligament thickness and muscle/collagen ratio influence the character of these hammock-like structures which are essential for the function of the pelvic floor to prevent the female pelvic organs from descending ${ }^{16}$. In the course of pregnancy, the parts of uterus do not grow proportionally. The uterine cervix, though infiltrated, increases only a little, while the uterine corpus increases much more. The course and winding of the uterine artery is configurated according to this disproportion ${ }^{15}$.

The features of the uterine scar dehiscence differ in relation to timing of the examination (in the third trimesters vs. in non-pregnant uterus) and the method of evaluation ${ }^{8,10,11}$. The risk of uterine scar dehiscence increases with number of repeated SCs, in emergency SC or when $\mathrm{SC}$ is performed due to intraovular infection ${ }^{10,11}$. Possible infection can hinder the healing process in the lower uterine segment which has a poorer vascular perfusion in contrast to the uterine body ${ }^{15}$. In some patients anatomical abnormalities that develop in relation to the scar can give rise to clinical symptoms such as menorrhagia, lower abdominal pain, dyspareunia, and dysmenorrhea. Uterine scar tissue in the lower segment can cause significant changes, including distortion and widening of the lower uterine segment, overhang of the endometrium above the scar or its polyp formation. In microscopic view lymphocytic infiltration, capillary dilatation and iatrogenic adenomyosis can be also found ${ }^{17}$.

Uterine retroflexion can also negatively influence the healing process as we found in our patient No II. This could be caused by reduced vascular perfusion due to stretching of the lower uterine segment and decreased collagen production. The location of the incision on the lower segment can also influence the healing. Scars with defects are usually found lower than intact scars ${ }^{13}$.

The management of silent dehiscence of the scar after previous SC varies and depends on the pregnant woman. Hamar et al. described successful expectant management of the dehiscent scar after previous SC which was found in the second trimester ${ }^{18}$.

Currently, many couples demand infertility treatment for various reasons. Many operations are performed on the uterus to improve the chances of fertility, e.g. uterine septum ablation or uterine myoma removal ${ }^{19}$. After any gynaecological operation on the uterus, women should be informed about possible risk of dehiscence or rupture of the uterus in the scar, particularly during pregnancy when the uterus is exposed to maximal strain of the tissues. The uterus is often operated in the uterine body, the active part of the uterus, where muscles are replaced by less functional avascular scar tissue.

Also women who have tried to become pregnant and have undergone any uterine operation have to be informed about possible risks for the future pregnancies. All four of our patients were extensively instructed about possible risk during IVF and ET treatment and later in pregnancy. Before stimulation the tentative use of catheter for embryo transfer was performed to ensure that the embryo transfer could proceed smoothly. Trans-abdominal ultrasound guided embryo transfer was performed with a semi-filled urinary bladder to enable the procedure. In all cases the catheter with embryo went smoothly across the area of the dehiscent scar.

According to our experience, IVF and ET infertility treatment can be offered as an option despite the dehiscent uterine scar in lower uterine segment after previous Caesarean section. These women have to be well informed about the risk and carefully monitored during their pregnancies. Only one embryo can be transferred to decrease the risk of multiple pregnancy. The uterine scar should be monitored at least once a month during pregnancy and more frequently in the third trimester. Elective $\mathrm{SC}$ has to be performed before the expected date of delivery.

\section{ABBREVIATIONS}

BMI, Body mass index; ET, Embryo transfer; GS, Gestational sac; hCG, Human chorionic gonadotropin; IVF, In vitro fertilization; PET, Preeclampsia; SC, Caesarean section; SE, Salpingectomy; US, Ultrasound.

\section{ACKNOWLEDGEMENTS}

The study was supported by the grant of the International Grant Agency of the Ministry of Health of the Czech Republic No. NH 6611-3.

Authorship contributions: IO, JB, RF, MD, BH: literature search; RF, IO, MB, ZB, MD: manuscript writing; IO, RF, JB: study design; IO, RF, JB, MD, BH, DP, MB: data collection; IO, RF, JB, MD, BH: data analysis; IO, RF, DP, SL: data interpretation; RF, MB, ZB, SL: figures; IO, SL: final approval.

Conflict of interest statement: The authors state that there are no conflicts of interest regarding the publication of this article.

\section{REFERENCES}

1. Dodd JM, Anderson ER, Gates S. Surgical techniques for uterine incisures and uterine closure at the time of caesarion section. Cochrane Database of Systematic Reviews, 2008 Jul 16;(3):CD004732. doi: 10.1002/14651858.CD004732.pub2. 
2. Osser OV, Valentin L. Risk factors for incomplete healing of the uterine incision after Caesarean section. BJOG 2010;117:1119-26.

3. Wagner MS, Bédard MJ. Postpartum uterine wound dehiscence: a case report. J Obstet Gynaecol Can 2006;28:713-15.

4. Jurkovic D, Hillaby K, Woelfer B, Lawrence A, Salim R, Elson C. Firsttrimester diagnosis and management of pregnancies implanted into the lower uterine segment Cesarean section scar. Ultrasound Obstet Gynecol 2003;21:220-7.

5. Ben Nagi J, Ofili-Yebovi D, Marsh M, Jurkovic D. First trimester Cesarean scar pregnancy evolving into placenta previa/accrete at term. J Ultrasound Med 2005;24:1569-73.

6. Monteagudo A, Carreno C, Timot-Tritsch IE. Saline infusion sonohysterography in nonpregnant woman with previous Cesarean delivery: the "niche" in the scar. J Ultrasound Med 2001;20:1105-15.

7. Rozenberg P, Goffinet F, Philippe HJ, Nisand I. Ultrasonographic measurement of lower segment to assess risk of defects of scarred uterus. Lancet 1996;347:281-4.

8. Asakura H, Nakai A, Ishikawa G, Suzuki S, Araki T. Prediction of uterine dehiscence by measuring Lower uterine segment thickness prior to the onset of labor. J Nippon Med Sch 2000;67:352-6.

9. Jastrow N, Chaillet N, Rozenberg S, Moreney AM, Lacasse Y, Bujold E. Sonographic lower uterine segment thickness and risk of uterine scar defect: a systemic revue. J Obstet Gynaecol Can 2010;32:231-7.

10. Regnard C, Nosbusch M, Fellemans C, Benali N, Van Rysselberghe $\mathrm{M}$, Barlow P, Rozenberg S. Cesarean section scar evaluation by saline contrast sonohysterography. Ultrasound Obstet Gynecol 2004;23:289-92.
11. Ofili-Yebovi D, Ben-Nagi J, Sawyer E, Yazbek J, Lee C, Gonzales J, Jurkovic D. Deficient lower-segment Cesarean section scars: prevalence and risk factors. Ultrasound Obstet Gynecol 2008;31:72-7.

12. Donnez O, Jadoul P, Squifflet J, Donnez J. Laparoscopic repair of wide and deep uterine scar dehiscence after caesarean section. Fertil Steril 2008;89:974-80.

13. Osser OV, Jokubkiene L, Valentin L. High prevalence of defects in Cesarean sections scars at transvaginal untrasound examination. Ultrasound Obstet Gynecol 2009;34:90-7.

14. Phillipe HJ, Karanough S, Rozenberg P, Dien DT, Nisand I.Transvaginal surgery for uterus scar dehiscence. Eur J Obstet Gynecol Reprod Biol 1997;73:135-8.

15. Dylevsky I, Druga R, Mrazkova O. Functional Anatomy of Human Body. Praha: Grada; 2008. p397-412.

16. Reay Jones NH, Healy JC, King LJ, Saini S, Shousha S, Allen-Mersh TG. Pelvic connective tissue resilience decreases with vaginal delivery, menopause and uterine prolapse. Br J Surg 2003;90(4):466-72

17. Hugh M.Surgical Pathology of the Lower Uterine Segment Caesarean Section Scar: Is the Scar a Source of Clinical Symptoms? International Journal of Gynecological Pathology 1995;14(1):16-20.

18. Hamar BD, Levine D, Katz NL, Lim KH. Expectant management of uterine dehiscence in the second trimester of pregnancy. Obstet Gynecol 2003;102:1139-42.

19. Hasbargen U, Summerer-Moustaki M, Hillemanns P, Scheidler J, Kimmig R., Hepp H. Uterine dehiscence in a nullipara, diagnosed by MRI, following use of unipolar electrocautery during laparoscopic myomectomy. Human Reproduction 2002;17:2180-2. 